\title{
Working with Group-Tasks and Group Cohesiveness
}

\author{
Khoirul Anwar ${ }^{1}$ \\ ${ }^{1}$ English Language Education Department, University of Muhammadiyah Gresik, Indonesia \\ Correspondence: Khoirul Anwar, University of Muhammadiyah Gresik, Jl. Sumatera 101 GKB Randu Agung, \\ Gresik, Indonesia. E-mail: anwarkhoirul41@gmail.com
}

Received: January 8, 2016

doi:10.5539/ies.v9n8p105

\author{
Accepted: February 9, $2016 \quad$ Online Published: July 26, 2016 \\ URL: http://dx.doi.org/10.5539/ies.v9n8p105
}

\begin{abstract}
This study aimed at exploring the connection between the use of group task and group cohesiveness. This study is very important because the nature of the learner's success is largely determined by the values of cooperation, interaction, and understanding of the learning objectives together. Subjects of this study are 28 students on the course Teaching English for Young Learners at the University of Muhammadiyah Gresik. After the application of group work activities during the learning process, all subjects are given questionnaires and some are interviewed to make sure the group cohesiveness. The results showed that the group work activities had settled the group cohesiveness mainly to the dominance of group pride, interpersonal attractions, and commitment to tasks of the group.
\end{abstract}

Keywords: group task, group cohesiveness

\section{Introduction}

A group is the integration of two or more individuals who are connected to each other through social relationships. Some important things to have in the group are communication, influence, interaction, interdependence, interrelation, shared identification, shared tasks and goals, structure and system (Forsyth, 2006).

A study group is essentially all group efforts to help each other learn optimally. Thus there are at least four important things that must be considered for the effort of cooperative learning to function, either as motivation, social cohesion, development and cognitive elaboration. All the four important things should be a mutually reinforcing cohesion when learning takes place. In the first aspect, in view of Slavin (2014), motivationalist found a group bonding will help achieve the group's performance and ultimately success will be the success of the group together and motivate learners to be more persistent again in optimizing their performance in the group. Thus the motivation is always important affiliated with a joint work in study groups. The second aspect, namely social cohesion perspective, this includes the importance of cooperative learning impact against a strong desire to help others, especially members of other groups who did not master. Here we find the existence of a good social cohesion and quality where members are less able to get help from other members who are better able to jointly achieve group goals. The third and fourth aspects, namely on cognitive development and learning, can be explained that when learners undertake cooperative partnership, this will automatically happen the development of critical analysis of each group member. The development of critical analysis of this happens because the group members are often faced by the problem solving and task completion continuously.

Students who are already motivated to learn is caused by a variety of interrelated elements that include teachers, assignments, and student groups. Because they have already been confidence, so their perception of classroom learning and attitudes affect their efforts to improve achievement. Inctrinsic motivation has a good tendency in language learning towards an increase in the level of proficiency (Colibaba, 2009). The good relation between group work and student motivation is also shown by Anwar's (2015) study especially on a constructive teaching model for adult learners which shows that interaction in group work activities had strenghten students' motivation to master teaching materials. Thus, student group and student motivation are inter-related to gear prospective attitudes to learn English and finally achieve better language proficiency (Kalvodova, 2008; Kuo, 2009).

In cooperative learning, Slavin (2006) asserts that members of the group consists of a variety of learners who have a diversity of skills to work together to achieve the learning objectives. Therefore, in cooperative learning, 
learners are given some skills that can help them maximize the cooperation of members to succeed in the task group that is the ability to listen actively, the ability to be a good speaker, the ability to always avoid demeaning other members, and the ability to always accept others as new members. Furthermore, he explains that the cooperative learning activities can be carried out in at least of three forms, of which is learning group that aims to discover where each member to help understand each other and understand the theory or a particular application. After that the group discussions are geared to ensure the best findings. The final step is to make sure all groups had finished working and to get something that can be learnt by following the quiz from teachers.

According to Ronald and Rivas (2005), the strategies needed to maximize the group dynamics are as follows:

- Identify the group dynamics during the group interaction.

- Assess the impact on the group dynamics and group members as part of the group as a whole.

- Assess the impact of group dynamics of group members from various ethnic backgrounds and social and economic.

- Assess the impact of group dynamics today on the utilization of the group in the future.

- Facilitate and guide the development dynamics of the group members.

In the study group, cohesiveness or group cohesion is the key to sustain the success of the group task. Group job performance is definitely linked and influenced by the group's success to build the cohesion of all the interests and contributions of group members, which in turn can result in learning achievement in the group task. As noted by Dornyei (2009), there are three main elements that can affect group cohesiveness in learning, namely:

1) Interpersonal attraction: There is a strong desire to love the members of the group naturally with rational and realistic objectives to promote common goals.

2) Commitment to task: A strong desire to have and be a member of the group because of the interest in completing the task, in other words, the feeling of individual involvement of the group is more due to the bonding strength of the group's goals.

3) Group pride: A strong desire to join the group because of the prestige that comes as part of the membership of the group.

Although any one of these three elements in the group, but ideally the blend of more than one elements or even coherence of all these components becomes a driving force of better and stronger group cohesion. In this case, the success of group cohesiveness is also supported highly by effective leadership of teachers as well. Teachers who succeed in group cohesiveness are those who are able to focus their students on a common goal and able to encourage members of the group to work as a team. Thus the teacher should be an effective facilitator and leader to understand the different models of leadership of the group in which the success or not depends on the group support to lead to independent learning (Gałajda, 2012; Burke, 2011).

To affirm the cohesion of the group, Dornyei (2009) describes the characteristics of a group that has a strong cohesion as follows:

1) The learning atmosphere of mutually-welcomed and appreciate one another so that shows signs of strong mutual desire and sharing.

2) Mutual to pay attention to one another.

3) Insist on and loyal to his group but also welcome and convince others to join.

4) Pay attention to group norms and oppose efforts that lead to the destruction of the group.

5) Participate in group voluntarily and pleased to work with others.

6) Easy to cooperate with anyone who is in the group members, so that the group task can be changed flexibly.

7) Actively participate in group activities and always ready to share personal experiences with others.

8) Frequently use the term "we" when conveying the idea and can even produce a special group jargon.

9) Have a competitive relationship with parties outside the group as well.

10) Easy to express satisfaction of group experience.

11) Participate more easily with one another within the group or outside the group.

In general, it appears that all the above characteristics will flourish when learning atmosphere in the communicative situation in which all members of the group provide optimal contribution in the success of the 
process of the completion of group tasks. Thus, the choice of the use of interactive and communicative learning methods presents a good opportunity to increase the cohesiveness of the group, so that the ultimate goal of learning can be achieved very well.

The next concern is the importance of considering the application of communicative learning strategies optimally, especially in learning the language because the chances of cohesion in the group to learn more is influenced by the varieties and types of learning activities undertaken by language learners. Some ways that need to be taken into consideration in the implementation of cohesion that optimizes learning group to complete the tasks are:

1) Learning from each other in the group and the class.

2) Providing a frequent interaction touch to fellow learners.

3) Encouraging the cooperation of the students.

4) Developing and encouraging the experience of a good group and organizing group cohesiveness opportunities inside and outside the classroom.

5) Developing a competition between groups

6) Provision of models and total support of teachers as a whole is necessary.

The six types of activities above do help increase group cohesion in the classroom, yet some previous ideas signaled the group's activities both inside and outside the classroom. Especially outdoors activities would greatly help the cohesion of which is competition, crossing the river, games, climbing ropes, and other competitive games either individually or in groups.

The above brief review indicates the importance of group cohesiveness in optimizing the role of assignments in study groups so as to provide optimal impact of learning outcomes. Therefore, this study aimed to identify the level of group cohesiveness after the application of group work activities.

\section{Research Method}

This research is a mixed method in which data is collected in two ways: using a questionnaire and observation. The questionnaire is necessary to ensure the level of group cohesion that occurs based on the opinion given in accordance with the preferred level of respondents to the ten questions prepared. Ten of these questions are based on the main criteria according to the theory that has been put forward by Dornyei (2009) that consists of level of interest and the interest of the respondents in interacting with others naturally to advance common goals (interpersonal attraction), commitment of who is truly in completing the task group (commitment to tasks), and the prestige or the loyalty of the group in completing tasks together (group pride).

Observations are carried out in the classroom, especially in the subject of Teaching English for Young Learners who have applied four working group meetings in English Language Study Program at University of Muhammadiyah Gresik. By applying team teaching, in four meetings, the lesson plan of the implementation of learning is prepared by the four teachers who are members of the Lesson Study program. Briefly this process is done in three stages of learning, namely Plan, Do and See. Plan is the planning stage prior to the implementation of learning in the classroom. In stage of plan, four team members of lesson study establishes a model implementation of group work activity followed by simultaneously establish planning procedures used. Do stage is to implement the agreed strategy of planning in four meetings with the lecturer as well as determine its model. See stage is the stage of discussion conducted by four members of the team to evaluate the implementation process of learning that has been used in every $\boldsymbol{D o}$, so there needs improvement to the implementation of the strategy at the next meeting. Observations made in the study is related to the stage of $\boldsymbol{D o}$ alone or in stages during the implementation of the four meetings that have been executed by the model lecturers.

The learning process in the subject of English for Young Learners fully implemented the learning model of group-work activities that use the procedures or steps as follows:

1) Ask learners to divide into groups of their own.

2) Instruct tasks to each group.

3) Allow time for discussion.

4) The small group made a presentation in their own.

5) Make presentations to other groups as well as a presentation for the class.

This activity is repeated so that when all the group activities are completed, again to form another new group 
with different members by providing a new task to the new group, and so on up to four times until all the meetings have been met and implemented. All of these meetings have been recorded and a questionnaire is given to all 28 students after the class meeting is completed. Along with the process of collecting data, during the observation is made, the researcher then applied the three stages of data analysis of the data reduction (where researchers create scripts observations at every meeting), and then perform data display (where researchers simply choose the activity or activities associated with indicators of group cohesiveness alone), and the last is doing conclusion that is to make a summary of the findings and draw conclusions from the two previous processes.

\section{Results and Discussions}

The following section presents the results of the research by presenting two main findings namely the results of the questionnaire and observation.

To measure the group cohesiveness in completing the task, a questionnaire then is drafted to a number of 28 (twenty eight) students by asking respondents to fill out with the category options of strongly agree with the weight of 6 , agree 5 , fairly agree 4 , slightly disagree 3 disagree 2 , and strongly disagree 1 . Detail recaps of the results of this questionnaire are described in Table 1.

Table 1. The results of questionnaire

\begin{tabular}{llcccccc}
\hline No & Items & 1 & 2 & 3 & 4 & 5 & 6 \\
\hline 1. & The atmosphere of mutual respect & 0 & 0 & 0 & 0 & 2 & 26 \\
2. & Mutual attention & 0 & 0 & 0 & 0 & 24 & 4 \\
3. & Members of the group have a strong loyalty & 0 & 0 & 0 & 0 & 24 & 4 \\
4. & Allows to receive members of other groups with pleasure & 0 & 0 & 0 & 0 & 23 & 5 \\
5. & Holding group norms well & 0 & 0 & 0 & 0 & 5 & 23 \\
6. & Participate in group activities voluntarily & 0 & 0 & 0 & 0 & 20 & 8 \\
7. & Easily collaborate with anyone & 0 & 0 & 0 & 0 & 20 & 8 \\
8. & Ready to share experiences and help others & 0 & 0 & 0 & 0 & 26 & 2 \\
9. & Always proud of the accomplishments and goals together & 0 & 0 & 0 & 0 & 24 & 4 \\
10. & Easy to communicate inside and outside of the study group & 0 & 0 & 0 & 3 & 20 & 5 \\
& Average & 0 & 0 & 0 & 0.3 & 18.8 & 8.9 \\
& & & & & $(1.07 \%)$ & $(67 \%)$ & $(31.7 \%)$ \\
\hline
\end{tabular}

Results of the questionnaire from respondents above show that in general all respondents agree on the great benefits of group work that has been done during the application of learning in the classroom. Based on the average of the answers given, as many as $67 \%$ of respondents agree that the cohesion of their group is more solid and even $31.7 \%$ of them stated strongly agree to the cohesiveness of the group. Only about $1.07 \%$ expressed slightly agree to the advent of group cohesion. However, the above data indicate the presence of group cohesion for completion of tasks in the classroom.

Results of the questionnaire are reinforced by the observation that has been done in the classroom with a detail description as follows:

Student 1: The technique that we use is brainstorming... the teacher tries to make the students active and build the students' background knowledge, for example the teacher uses some questions like why do you like vegetables .... Can you mention the kinds of vegetables...

Teacher clarifies: How do the students answer?

Student 2: (directly the second student answers the question)... by giving yes-no answer and then give explanations after that especially why it is yes and no....

Teacher clarifies again: What group do you choose to continue answering the questions?

Student 2: ... we think the third group can continue explaining the techniques of concept mapping... 
In the above quotes of conversation, group members always use the word choice opener of using "we" at the beginning of their presentation. Members of the group in the presentation are three people, but still they do not at all use the word "I" when conveying ideas of the group. The choice of words used by the group shows strong group cohesion with the group pride where all members of the group feel proud as the real group doer instead of using the wording of the designation of individual members of the group. Student 2 who helps Student 1 in clarifying the explanation above is also seen as their cohesion with the group showing a commitment to perform the task well. Furthermore, when the second student also ask other groups to continue the explanation of the concept mapping, here, group cohesiveness is also indicated by the presence of interpersonal attraction not only in the group but also between groups.

The next observation results are captured from group $\mathrm{C}$ at meeting 2 in the following section:

Student 1: ... Ok, for our group, we choose technique concept mapping...

Teacher: ...For example?

Student 2: The teacher asks the students about vegetables,... and then,... by using examples...by asking ... what vegetables do you like?... and then the students answer by using their own ideas. ...

Student 1: (directly helps the first student by continuing the ideas) ....and then the teacher gives instruction to the group work for examples one student asks the other students in the group work by using questions...

Student 3 (from group D): ... I think the concept mapping ... the teacher gives a column and ask the students to select the pictures that are appropriate with the column ...such kind of this one... (the student shows the examples from her book).

(Conversations taken from the Group C meeting 2)

Quotations above show that cohesion also occurs in the group demonstrated by a trend of using "we" in the presentation of the group, in which it means the existence of an element of group pride. Then, the next cohesiveness is shown by the response given by student 1 in connecting the student 2 to help add an explanation especially on aspects that have been described in the use of concept mapping in learning English in class. Efforts to help explain by members of other groups are also performed by student 3 (although from group $\mathrm{D}$, the different group) which aims to demonstrate the existence of interpersonal attraction in completing the group task.

The above data is also confirmed by the excerpt below which is primarily taken from Group B at meeting 3 as follows:

Student 1: We are from second group and ...in here, our learning media is for teaching speaking and listening, and then the goal of the activity... the students have to listen to the story ... and then the students also can mention the characters or ... the way of the story. The media used is a puppet to tell story.

Student 2: ... after Heru tells us about the story, what do you get the message?... (the question is given to other groups)... What are the characteristics of stepmother? ... What about the characteristics of the green puppet?...

(Conversations taken from Group B meeting 3)

All three elements of group cohesiveness are also indicated in the above quotes in that the use of the word "we" as part of their group pride by student 1 . This is also supported by the role of student 2 , who has helped explain of showing strong commitment to finish the task and also his attempts of helping clarify the theme by asking questions to other groups, these all thus have demonstrated the existence of interpersonal attraction.

The following final quote is to reinforce the group cohesiveness that arises during the implementation process of group work:

Student 1: ...our group, eeh ..the topic of our group is about numbers and for the first grade of....and the skill is listening and speaking and ...the media that we use is visual media and ... excuse me please, Adji and friends(of group C), would you please to repeat after me...(the members of group C follow all instruction).

Student 2: ... we think that we already learnt about numbers from our group presentation. The next activity is that we want to divide you into two groups ... (asking other groups to succeed the presentation by involving them in the activity).

(Quotation taken from Group D meeting 4)

The above quotes further strengthen the group pride (with the use of "our group"), interpersonal attraction (by asking another group, namely Group $\mathrm{C}$ to follow all the instructions), and commitment to Tasks (indicated by a 
student 2 who give an additional explanation and at the same time provide additional activities that demonstrate a commitment to complete the task earnestly and well).

The above observation results have demonstrated the cohesion of the group after the implementation of group work. These data thus supports questionnaire results that also showed the presence of group cohesiveness of answers to some questions that have been given by the researchers. In general, the data from the findings of this study indicates a very close relationship between the implementation of the work group and cohesiveness characterized by three pillars, namely the dominance of group pride, interpersonal attraction, and commitment to tasks.

Results of this study certainly support several previous studies (Carreira, 2006; Bernaus \& Gardner, 2009; Anwar, 2010; Anwar, 2015), including the research done by Harun and Mahmood (2012) where there is a relationship between group cohesiveness and performance, especially with respondent identification of task relationships, social cohesion, and performance within the framework of the progress of the movement. Data is taken from 371 respondents through a questionnaire. Results of the study showed that the group cohesiveness was significantly correlated with the performance of the organization. In addition, both terms of social cohesion and task were significantly correlated with the performance of the organization has already been predicted in the hypothesis. The study also found that the cooperative task can potentially increase the cohesion of the group.

Group cohesiveness is the relationship between members of the group with very mutual ties which have impact to obtain a common group goal (Rinnankoski, 2001). In a research that has been conducted on a group with 14 members of multicultural representing 9 countries in a European company that had headquarters near Nederland, showed the results of research that support most previous researches with the positive impact on the importance of group cohesiveness in the group work.

Not only in the multicultural group, these results are also very concerned with group cohesiveness of group work in companies, especially a research conducted by Shin and Park (2009) about the group cohesiveness at 249 workers in the company of Korea which showed that group cohesiveness has a positive effect on the competence of the group's performance so it is possible to help achieve the company's main performance better. In this study, the data has shown that the linkage group also leads to the quality of performance in company.

This study would also support the research that has been done by Borkar and Kesarkar (2012) who had proven the effects of cooperative learning strategy and cohesiveness. Their studies reveal that cooperative learning strategy has better impacts on group cohesiveness especially in experimental research in Indian school. The research also promotes the use of cooperative learning strategy as the best way of building cohesiveness at school environments.

Thus, the results of this study certainly do not only support but also complement the findings of previous studies in that all lead to the very close relationship between group work and group cohesiveness. The things that need attention of the findings in this study is that of the three elements in group cohesiveness, group pride is very dominating in group work, followed by interpersonal Attractions and commitment to tasks.

\section{Conclusion}

The research with the purpose of the analysis of the relationship between group work and group cohesiveness can be concluded that:

1) Group work activities have a positive impact on the group cohesiveness in the study group. This is proven by the emergence of features that have been common in the formation of group cohesiveness that is the interpersonal Attractions, commitment to tasks, and group pride.

2) The results of this study have also demonstrated that group cohesion has been shown to us by the advent of the dominance of group pride as an indicator of the most prominent and consecutively followed by interpersonal attractions and the last is a commitment to tasks.

3) The research suggests that group cohesiveness needs to get serious attention especially by teachers since the success of the group is the beginning of the establishment of social values and cooperation. This can certainly be beneficial for the hope of the learners, especially for their life provision in the future.

4) Further researches on group cohesiveness is still necessary to proceed to any further extent of both qualitative and quantitative, especially with regard to the importance of group cohesiveness contribution to the development of students' characters, especially for the setting of foreign language learners.

\section{References}

Anwar, K. (2010). Penguatan Self Concept siswa melalui Cooperative learning. Proceeding International 
Seminar: Universiti Pendidikan Sultan Idris Malaysia.

Anwar, K. (2015). A Constructive Teaching Model in Learning Research Concept for English Language Teaching Students. International Education Studies, 8(5), 52-68. http://dx.doi.org/10.5539/ies.v8n5p62

Bernaus, W., \& Gardner. (2009). Teachers' motivation, classroom strategy use, students' motivation and second language achievement. JPOOSRÉT AM LAINNUGEULA VRUEMZ 12, junio 2009. Retrieved from http://www.ugr.es.

Borkar, U., \& Kesarkar, M. (2012). Cooperative Learning Strategy and Group Cohesiveness. Voice of Research, 1(2), June 2012. Retrieved December 27, 2015, from http://www.voiceofresearch.org

Burke, A. (2011). Group Work: How to Use Groups Effectively. The Journal of Effective Teaching, 11(2), 87-95.

Carreira, Matsuzaki, \& Junko. (2006). Motivation for Learning English as a Foreign Language in Japanese Elementary Schools. JALT Journal, 28(2). Retrieved from http://www.jalt-publications.org

Colibaba, A. C. (2009). Group cohesion in the English language class. SYNERGY, 5(2). Retrieved December 30, 2015, from http://synergy.ase.ro/issues/2009-vol5-no2/07-group-cohesion-in-the-english-language-class.pdf

Dornyei, Z., \& Murphy, T. (2009). Group Dynamics in Language Classroom. UK: Cambridge University Press.

Forsyth, D. R. (2006). Group Dynamics. California: Thomson Wadsworth.

Gałajda, D. (2012). Teacher's Action Zone in Facilitating Group Dynamics. LINGVARVM ARENA-VOL. 3-ANO 2012-89-101. Retrieved from http://ler.letras.up.pt/uploads/ficheiros/10951.pdf

Harun, M, Z, M., \& Mahmood, R. (2012). The Relationship between Group Cohesiveness and Performance: An Empirical Study of Cooperatives Movement in Malaysia. International Journal of Cooperative Studies, 1(1), 15-20.

Kalvodová, H. (2008). Motivation in English Lessons (Diploma Thesis at Masaryk University Brno Faculty of Education). Retrieved from https://is.muni.cz/th/104714/pedf_m/diplomova_prace.pdf

Kuo, J. L. (2009). Exploring The connection Between Learner Interest and Group Cohesion in A Taiwanese EFL Classroom (A Dissertation of Doctor of Education at Faculty of Education of Griffith University). Retrieved from https://www120.secure.griffith.edu.au/rch/file/f3a3a173-bd0d-dd08-f007-d5006b888cfe/1/Kuo_2012_ 02Thesis.pdf

Rinnankoski, E. (2001). Social Identification and Group Cohesiveness in a Multicultural Group Work. Retrieved from https://jyx.jyu.fi/dspace/bitstream/handle/123456789/11656/rinnanko.pdf?sequence=1

Shin, S. Y., \& Park, W. W. (2009). Moderating Effects of Group Cohesiveness in Compete ncy-Performance Relationships: A Multi-Level Study. Journal of Behavioral Studies in Business, 1.

Slavin, R. E. (2006). Educational Psychology: Theory and Practice. Boston: Pearson Education, Inc.

Slavin, R. E. (2014). Cooperative Learning and Academic Achievement: Why Does Groupwork Work? Anales de Psicología, 30(3), 785-791. Universidad de Murcia, Murcia, España. $\mathrm{http}: / / \mathrm{dx}$. doi.org/10.6018/analesps.30.3.201201

Toseland, R. W., \& Rivas, R. F. (2005). An Introduction to Group Work Practice. Boston: Allyn \& Bacon. Retrieved from http://www.ablongman.com

\section{Copyrights}

Copyright for this article is retained by the author(s), with first publication rights granted to the journal.

This is an open-access article distributed under the terms and conditions of the Creative Commons Attribution license (http://creativecommons.org/licenses/by/4.0/). 